\title{
HUBUNGAN DUKUNGAN KELUARGA TERHADAP PASIEN SKIZOFRENIA DI UPTD PUSKESMAS SIBULUE KECAMATAN SIBULUE KABUPATEN BONE TAHUN 2018
}

\author{
A. Artifasari \\ Akademi Keperawatan Batari Toja \\ Alamat Korespondensi:(artifasari383@gmail.com/ 082148848131)
}

\begin{abstract}
ABSTRAK
Skizofrenia merupakan penyakit kronis, kompleks, dan heterogen yang mempengaruhi sebagian besar fungsi dari aspek psikologis, dampak yang berat akibat individu dengan skizofrenia dapat menghancurkan aspek kekeluargaan, peranan dalam lingkup social, dan ketergantungan terhadap obat antipsikotik sebagai faktor utama dalam mencegah terjadinya kekambuhan dan munculnya gejala-gejala yang ada pada pasien.Tujuan penelitian ini adalah untuk mengetahui hubungan dukungan keluarga terhadap pasien skizofrenia di uptd puskesmas sibulue kecamatan sibulue kabupaten bone. Penelitian ini merupakan jenis penelitian kuantitatif dengan desain penelitian deskriptif analitik dengan pendekatan cross sectional. Pengambilan sampel pada penelitian ini dilakukan dengan teknik purposive sampling dan jumlah sampel sebanyak 41 responden. Instrumen yang digunakan adalah lembar kuesioner. Data dianalisis menggunakan program SPSS dengan uji stastistik Chi-Square dan tingkat kemaknaan $\rho$ Value $<0,05$. Berdasarkan hasil analisis hubungan antara peran keluarga dengan kepatuhan berobat diperoleh nilai $\rho=0,023$ berarti ada hubungan bermakna antara peran keluarga dengan kepatuhan berobat. Sedangkan hubungan antara efikasi diri dengan kepatuhan berobat diperoleh nilai $\rho=0,016$ berarti ada hubungan bermakna antara efikasi diri dengan kepatuhan berobat. kesimpulan dalam penelitian ini adalah terdapat hubungan antara peran keluarga dan efikasi diri pasien dengan kepatuhan berobat pasien TB di Balai Besar Kesehatan Paru Masyarakat. Diharapkan adanya upaya untuk meningkatkan peran keluarga serta efikasi diri pasien sehingga meningkatkan kepatuhan berobat pada pasien TB Paru.
\end{abstract}

Kata Kunci : Dukungan Keluarga, Skizofrenia

\section{PENDAHULUAN}

Skizofrenia merupakan suatu deskripsi sindrom dengan variasi penyebab dan perjalanan penyakit yang luas, serja sejumlah akibat yang bergantung pada interaksi pengaruh genetik, fisik dan social budaya (muslim,2013).

Menurut World Health Organization (2017) pada umumnya gangguan mental yang terjadi adalah gangguan kecemasan dan gangguan depresi. Diperkirakan $4,4 \%$ dari populasi global menderita gangguan depresi, dan $3,6 \%$ dari gangguan kecemasan. Jumlah penderita depresi meningkat lebih dari $18 \%$ antara tahun 2005 dan 2015. Depresi merupakan penyebab terbesar kecacatan di seluruh dunia. Lebih dari $80 \%$ penyakit ini dialami orang-orang yang tinggal di negara yang berpenghasilan rendah dan menengah (WHO, 2017).

Laporan organisasi kesehatan dunia (World Health Organization/WHO) pada 2010 tentang Global Burden Disease menyebut, kini telah terjadi perubahan jenis penyakit yang menimbulkan beban bagi negara secara global. Sebelumnya, WHO menyebut kasus kematian ibu dan anak paling besar membebani negara, tetapi kini bergeser ke penyakit kronis, termasuk penyakit jiwa berat, misalnya skizofrenia. Penderita gangguan psikis dengan diagnosis skizofrenia tahun 2010 kurang lebih 24 juta jiwa di seluruh dunia. Dari jumlah 24 juta jiwa tersebut 1.928.663 juta jiwa tercatat berada di Indonesia, dengan kasus skizofrenia. Dalam laporan tersebut terdapat dalam pengkajian data di Indonesia dengan kasus skizofrenia mencapai 2,5\% dari total penduduk Indonesia.

Data Riskesdas 2013 memunjukkan prevalensi ganggunan mental emosional yang ditunjukkan dengan gejala-gejala depresi dan kecemasan untuk usia 15 tahun ke atas mencapai sekitar 14 juta orang atau $6 \%$ dari jumlah penduduk Indonesia. Sedangkan prevalensi gangguan jiwa berat, seperti skizofrenia mencapai sekitar 400.000 orang atau sebanyak 1,7 per 1.000 penduduk.

Gangguan jiwa dapat terjadi pada siapa saja dan kapan saja. Hasil analisis dari WHO sekitar 450 juta orang menderita gangguan jiwa termasuk skizofrenia. Riset Kesehatan Dasar yang dilakukan oleh Kementrian 
Republik Indonesia menyimpulkan bahwa prevalensi ganggunan mental emosional yang menunjukan gejala depresi dan kecemasan, usia 15 tahun ke atas mencapai sekitar 14 juta orang atau $6 \%$ dari jumlah penduduk Indonesia. Sedangkan prevalensi gangguan jiwa berat, seperti skizofrenia mencapai sekitar 400.000 orang atau sebanyak 1,7 per 1.000 penduduk. Jumlah gangguan jiwa berat atau psikosis/ skizofrenia tahun 2013 di Indonesia provinsi-provinsi yang memiliki gangguan jiwa terbesar pertama antara lain adalah Daerah Istimewa Yogyakarta $(0,27 \%)$, kemudian urutan kedua Aceh ( $0,27 \%)$, urutan ketiga sulawesi selatan $(0,26 \%)$, Bali menempati posisi keempat $(0,23 \%)$, dan Jawa Tengah menempati urutan kelima $(0,23 \%)$ dari seluruh provinsi di Indonesia (Riset Kesehatan Dasar, 2013) dan Sulawesi Selatan tercatat memiliki prevalensi gangguan mental emosional yang tinggi dengan prevalensi sebesar 9,3. uraian diatas, maka peneliti merasa perlu untuk melakukan penelitian tentang hubungan dukungan keluarga terhadap pasien skizofrenia di uptd puskesmas sibulue kecamatan sibulue kabupaten bone.

\section{BAHAN DAN METODE}

Lokasi, populasi dan sampel

Penelitian ini dilaksanakan di UPTD Puskesmas Sibulue Kecamatan Sibulue pada Bulan November s/d Desember 2018. Populasi dalam penelitian ini adalah pasien Skizofrenia dan bukan pasien skizofrenia serta keluarga dari klien gangguan jiwa yang mengalami tipe skizofrenia dengan jumlah sampel pada penelitian ini adalah 41 orang.

1. kriteria inklusi:
a. Keluarga yang memiliki anggota keluarga gangguan jiwa dengan diagnosa medis skizofrenia dan tidak terdiagonsa medis skizofrenia
b. Keluarga terlibat dalam perawatan klien sehari-hari, dan tinggal satu rumah dengan responden.
c. Mampu berkomunikasi atau menjawab pertanyaan (kooperatif).

2. kriteria eksklusi:
a. Tidak bersedia menjadi responden
b. Berusia di bawah 18 tahun
c. Keluarga yang tidak memiliki anggota keluarga gangguan jiwa dengan diagnosa medis skizofrenia

\section{Pengumpulan Data}

1. Data sekunder adalah data yang diperoleh dalam bentuk jadi dan telah diolah oleh pihak lain yang biasanya dalam bentuk publikasi.
2. Data primer adalah data yang dikumpulkan dan diolah sendiri oleh suatu organisasi atau perorangan langsung dari objeknya (Saryono 2014).

\section{Pengolahan Data}

1. Editing

Editing adalah tahapan kegiatan memeriksa validitas data yang masuk seperti memeriksa kelengkapan pengisian kuesioner, kejelasan jawaban, relevansi jawaban dan keseragaman suatu pengukuran.

2. Coding

Coding adalah tahapan kegiatan mengklasifikasi data dan jawaban menurut kategori masing-masing sehingga memudahkan dalam pengelompokan data.

3. Processing

Processing adalah tahapan kegiatan memproses data agar dapat dianalisis. Pemrosesan data dilakukan dengan cara memasukkan data hasil pengisian kuesioner ke dalam master tabel (Lapau, 2013).

Analisis data

1. Analisis Univariat

Digunakan untuk mendeskripsikan variabel penelitian guna memperoleh gambaran atau karakteristik sebelum dilakukan analisi bivariat. Hasil dari penelitian ditampilkan dalam bentuk distribusi frekuensi.

2. Analisis Bivariat

Analisis bivariat yang dilakukan adalah tabulasi silang antara dua variabel yaitu variabel independen dan dependen. Analisis bivariat yang digunakan untuk mengetahui hubungan terhadap objek penelitian adalah menggunakan uji chi square.

\section{HASIL PENELITIAN}

1. Analisa univariat

Tabel 1 Hubungan antara Dukungan Emosional dengan Pasien Skizofrenia di UPTD Puskesmas Sibulue Kecamatan Sibulue Kabupaten Bone Tahun 2018

\begin{tabular}{|c|c|c|c|c|c|c|}
\hline Dukungan & \multicolumn{4}{|c|}{ Skizofrenia } & \multirow{2}{*}{ Total } \\
\cline { 2 - 7 } $\begin{array}{c}\text { Emosion } \\
\text { al }\end{array}$ & \multicolumn{2}{|c|}{ Ya } & \multicolumn{2}{|c|}{ Tidak } & \multicolumn{2}{c|}{} \\
\cline { 2 - 7 } & $\mathrm{n}$ & $\%$ & $\mathrm{n}$ & $\%$ & $\mathrm{n}$ & $\%$ \\
\hline Jarang & 0 & 0 & 2 & 100,0 & 2 & 100,0 \\
\hline Sering & 14 & 63,6 & 8 & 36,4 & 22 & 100,0 \\
\hline Selalu & 7 & 41,2 & 10 & 58,8 & 17 & 100,0 \\
\hline \multicolumn{8}{|c|}{$p=0,126$} \\
\hline
\end{tabular}

Berdasarkan tabel 1, diketahui dari jumlah 41 responden proporsi dukungan emosional yang jarang menunjukkan yaitu $0 \%$ dengan skizofrenia lebih sedikit 
dibanding dukungan emosional yang jarang menunjukkan yaitu 100,0\% dengan tidak skizofrenia, proporsi dukungan emosional yang sering menunjukkan yaitu $63,6 \%$ dengan skizofrenia lebih tinggi dibanding dukungan emosional yang sering menunjukkan yaitu $36,4 \%$ dengan tidak skizofrenia, dan proporsi dukungan emosional yang selalu menunjukkan yaitu $41,2 \%$ dengan skizofrenia lebih sedikit dibanding dukungan emosional yang selalu menunjukkan yaitu $58,8 \%$ dengan tidak skizofrenia.

Setelah dilakukan analisis menggunakan uji Chi Square, diperoleh pvalue sebesar $0.126>\alpha 0.05$, dengan demikian dalam penelitian ini tidak diterima, dan dapat dinyatakan tidak terdapat hubungan antara dukungan emosional dengan pasien skizofrenia di UPTD Puskesmas Sibulue Kecamatan Sibulue Kabupaten Bone.

Tabel 2 Hubungan antara Dukungan Informasional dengan Pasien Skizofrenia di UPTD Puskesmas Sibulue Kecamatan Sibulue Kabupaten Bone Tahun 2018

\begin{tabular}{|c|c|c|c|c|c|c|}
\hline \multirow{3}{*}{$\begin{array}{c}\text { Dukungan } \\
\text { Informasi } \\
\text { onal }\end{array}$} & \multicolumn{4}{|c|}{ Skizofrenia } & \multirow{2}{*}{\multicolumn{2}{|c|}{ Total }} \\
\hline & \multicolumn{2}{|c|}{$\mathrm{Ya}$} & \multicolumn{2}{|c|}{ Tidak } & & \\
\hline & $\mathrm{n}$ & $\%$ & $n$ & $\%$ & $\mathrm{n}$ & $\%$ \\
\hline Jarang & 9 & 47,4 & 10 & 52,6 & 10 & 100,0 \\
\hline Sering & 6 & 60,0 & 4 & 40,0 & 10 & 100,0 \\
\hline Selalu & 6 & 50,0 & 6 & 50.0 & 12 & 100,0 \\
\hline \multicolumn{7}{|c|}{$p=0,807$} \\
\hline
\end{tabular}

Berdasarkan tabel 2, diketahui dari jumlah 41 responden proporsi dukungan informasional yang jarang menunjukkan yaitu 47,7 dengan skizofrenia lebih sedikit dibanding dukungan infomasional yang jarang menunjukkan yaitu $52,6 \%$ dengan tidak skizofrenia, proporsi dukungan informasional yang sering menunjukkan yaitu $60,0 \%$ dengan skizofrenia lebih tinggi dibanding dukungan informasional yang sering menunjukkan yaitu 40,0\% dengan tidak skizofrenia, dan proporsi dukungan informasional yang selalu menunjukkan yaitu $50,0 \%$ dengan skizofrenia sama dengan dukungan informasional yang sering menunjukkan yaitu $50,0 \%$ dengan tidak skizofrenia.

Setelah dilakukan analisis menggunakan uji Chi Square, diperoleh pvalue sebesar $0.807>\alpha 0.05$, dengan demikian dalam penelitian ini tidak diterima, dan dapat dinyatakan tidak terdapat hubungan antara dukungan informasional dengan pasien skizofrenia di UPTD
Puskesmas Sibulue Kecamatan Sibulue Kabupaten Bone.

b. Tabel 3 Hubungan antara Dukungan Instrumental dengan Pasien Skizofrenia di UPTD Puskesmas Sibulue Kecamatan Sibulue Kabupaten Bone Tahun 2018

\begin{tabular}{|c|c|c|c|c|c|c|}
\hline \multirow{2}{*}{$\begin{array}{c}\text { Dukungan } \\
\text { Instrume } \\
\text { ntal }\end{array}$} & \multicolumn{4}{|c|}{ Skizofrenia } & \multirow{2}{*}{ Total } \\
\cline { 2 - 7 } & \multicolumn{2}{|c|}{ Ya } & \multicolumn{2}{|c|}{ Tidak } & \multicolumn{1}{c|}{} \\
\cline { 2 - 7 } & $\mathrm{n}$ & $\%$ & $\mathrm{n}$ & $\%$ & $\mathrm{n}$ & $\%$ \\
\hline Jarang & 7 & 70,0 & 3 & 30,0 & 10 & 100,0 \\
\hline Sering & 5 & 35,7 & 9 & 64,3 & 14 & 100,0 \\
\hline Selalu & 9 & 52,9 & 8 & 41,7 & 17 & 100,0 \\
\hline \multicolumn{8}{|c|}{$p=0,249$} \\
\hline
\end{tabular}

Berdasarkan tabel 3, diketahui dari jumlah 41 responden Proporsi dukungan instrumental yang jarang menunjukkan yaitu $70.0 \%$ dengan skizofrenia lebih tinggi dibanding dukungan instrumental yang jarang menunjukkan yaitu 30,0\% dengan tidak skizofrenia, proporsi dukungan instrumental yang sering menunjukkan yaitu $35,7 \%$ dengan skizofrenia lebih rendah dibanding dukungan instrumental yang sering menunjukkan yaitu $64,3 \%$ dengan tidak skizofrenia, dan proporsi dukungan instrumental yang selalu menunjukkan yaitu $52,9 \%$ dengan skizofrenia lebih tinggi dibanding dukungan instrumental yang selalu menunjukkan yaitu $41,7 \%$ dengan tidak skizofrenia.

Setelah dilakukan analisis menggunakan uji Chi Square, diperoleh pvalue sebesar $0.249>\alpha 0.05$, dengan demikian dalam penelitian ini tidak diterima, dan dapat dinyatakan tidak terdapat hubungan antara dukungan instrumental dengan pasien skizofrenia di UPTD Puskesmas Sibulue Kecamatan Sibulue Kabupaten Bone.

c. Tabel 4 Hubungan antara Dukungan Penghargaan dengan Pasien Skizofrenia di UPTD Puskesmas Sibulue Kecamatan Sibulue Kabupaten Bone Tahun 2018

\begin{tabular}{|c|c|c|c|c|c|c|}
\hline Dukungan & \multicolumn{4}{|c|}{ Skizofrenia } & \multirow{2}{*}{ Total } \\
\cline { 2 - 7 } $\begin{array}{c}\text { Penghar } \\
\text { gaan }\end{array}$ & \multicolumn{2}{|c|}{ Ya } & \multicolumn{2}{|c|}{ Tidak } & \multicolumn{1}{c|}{} \\
\cline { 2 - 7 } & $\mathrm{n}$ & $\%$ & $\mathrm{n}$ & $\%$ & $\mathrm{n}$ & $\%$ \\
\hline Jarang & 4 & 66,7 & 2 & 33,3 & 6 & 100,0 \\
\hline Sering & 12 & 46,2 & 14 & 53,8 & 26 & 100,0 \\
\hline Selalu & 21 & 51,2 & 20 & 48,8 & 41 & 100,0 \\
\hline \multicolumn{6}{|c|}{$p=0,653$} \\
\hline
\end{tabular}

Berdasarkan tabel 4, diketahui dari jumlah 41 responden Proporsi dukungan penghargaan yang jarang menunjukkan yaitu $66,7 \%$ dengan skizofrenia lebih tinggi dibanding dukungan penghargaan yang jarang menunjukkan yaitu $33,3 \%$ dengan tidak skizofrenia, proporsi dukungan 
penghargaan yang sering menunjukkan yaitu $46,2 \%$ dengan skizofrenia lebih sedikit dibanding dukungan penghargaan yang sering menunjukkan yaitu 53,8\% dengan tidak skizofrenia, dan proporsi dukungan penghargaan yang selalu menunjukkan yaitu $51,2 \%$ dengan skizofrenia lebih tinggi dibanding dukungan penghargaan yang selalu menunjukkan yaitu $48,8 \%$ dengan tidak skizofrenia.

Setelah dilakukan analisis menggunakan uji Chi Square, diperoleh pvalue sebesar $0.635>\alpha 0.05$, dengan demikian dalam penelitian ini tidak diterima, dan dapat dinyatakan tidak terdapat hubungan antara dukungan penghargaan dengan pasien skizofrenia di UPTD Puskesmas Sibulue Kecamatan Sibulue Kabupaten Bone.

\section{PEMBAHASAN}

1. Hubungan antara Dukungan Emosional dengan Pasien Skizofrenia di UPTD Puskesmas Sibulue Kecamatan Sibulue Kabupaten Bone

Berdasarkan hasil penelitian yang dilakukan, maka diketahui bahwa total keseluruhan dukungan emosional pasien yang mengalami skizofrenia yang jarang, sering, dan selalu menunjukkan bernilai 21 orang $(51,2 \%)$ sedangkan, pasien yang tidak mengalami skizofrenia yang jarang, sering, dan selalu menunjukkan bernilai 20 orang $(48,8 \%)$.

Setelah dilakukan uji Chi Square, didapatkan nilai pvalue sebesar 0.126 , yang berarti $p$ value $0.126<\alpha 0.05$, dapat disimpulkan bahwa dukungan emosional tidak mempunyai hubungan yang signifikan dengan pasien skizofrenia di UPTD Puskesmas Sibulue Kcamatan Sibulue Kabupaten Bone.

Hasil penelitian ini sejalan dengan penelitian yang dilakukan oleh Diah Widodo (2002) dalam penelitian Esti Perdana Puspitasari "Hubungan Tingkat Pengetahuan Keluarga Tentang Perawatan Penderita Gangguan Jiwa Di Rumah Dan Tingkat Penerimaan Keluarga Terhadap Frekuensi Kekambuhan Di RSJ Pusat Lawang Dan RSJ Daerah Surabaya" Penelitian ini adalah penelitian korelasi, hasil penelitian ini menunjukkan bahwa tidak ada hubungan antara tingkat pengetahuan dan tingkat penerimaan keluarga terhadap penderita gangguan jiwa dengan frekuensi kekambuhan.

2. Hubungan antara Dukungan Informasional dengan Pasien Skizofrenia di UPTD
Puskesmas Sibulue Kecamatan Sibulue Kabupaten Bone

Berdasarkan hasil penelitian yang dilakukan, maka diketahui bahwa total keseluruhan dukungan informasional pasien yang mengalami skizofrenia yang jarang, sering, dan selalu menunjukkan bernilai 21 orang $(51,2 \%)$ sedangkan, pasien yang tidak mengalami skizofrenia yang jarang, sering, dan selalu menunjukkan bernilai 20 orang $(48,8 \%)$.

Hasil penelitian ini sejalan dengan penelitian yang dilakukan oleh Sri Wulansih \& Arif Widodo (2007) "Hubungan Antara Tingkat Pengetahuan Dan Sikap Keluarga Dengan Kekambuhan Pada Pasien Skizofrenia Di RSJD Surakarta" dengan hasil penelitian tidak ada hubungan yang signifikan antara tingkat pengetahuan dengan kekambuhan pada pasien skizofren. Hal ini ditunjukkan dengan perolehan nilai signifikan dari hubungan tingkat pengetahuan dengan kekambuhan sebesar 0,256 dengan $p>0,05$.

3. Hubungan antara Dukungan Instrumental dengan Pasien Skizofrenia di UPTD Puskesmas Sibulue Kecamatan Sibulue Kabupaten Bone

Berdasarkan hasil penelitian yang dilakukan, maka diketahui bahwa total keseluruhan dukungan instrumental pasien yang mengalami skizofrenia yang jarang, sering, dan selalu menunjukkan bernilai 21 orang $(51,2 \%)$ sedangkan, pasien yang tidak mengalami skizofrenia yang jarang, sering, dan selalu menunjukkan bernilai 20 orang $(48,8 \%)$.

Hasil penelitian ini sejalan dengan penelitian yang dilakukan oleh Hasmila Sari "Terapi Psikoedukasi Keluarga Terhadap Kemampuan Keluarga Dalam Merawat Klien Dengan Schizofrenia Di Rumah Sakit Jiwa Pemerintah Aceh" Hasil uji statistik Wilcoxon's matched pairs test menunjukkan tidak terdapat perbedaan kemampuan yang bermakna antara sebelum intervensi dengan sesudah dilakukan intervensi $(p>0,05)$, meskipun demikian terdapat peningkatan jumlah responden yang mempunyai kemampuan kognitif dan psikomotor yang lebih baik setelah intervensi. Penilaian kemampuan psikomotor responden akan lebih baik jika didukung dengan observasi proses latihan psikomotor keluarga dalam merawat klien secara langsung dengan memberikan pengetahuan dan latihan terstruktur serta konsisten sesuai dengan modul psikoedukasi keluarga yang telah disusun. 
4. Hubungan antara Dukungan Penghargaan dengan Pasien Skizofrenia di UPTD Puskesmas Sibulue Kecamatan Sibulue Kabupaten Bone

Berdasarkan hasil penelitian yang dilakukan, maka diketahui bahwa total keseluruhan dukungan penghargaan pasien yang mengalami skizofrenia yang jarang, sering, dan selalu menunjukkan bernilai 21 orang $(51,2 \%)$ sedangkan, pasien yang tidak mengalami skizofrenia yang jarang, sering, dan selalu menunjukkan bernilai 20 orang $(48,8 \%)$.

Hasil penelitian ini sejalan dengan penelitian yang dilakukan oleh Diah Widodo (2002) dalam penelitian Esti Perdana Puspitasari "Hubungan tingkat pengetahuan keluarga tentang perawatan penderita gangguan jiwa di rumah dan tingkat penerimaan keluarga terhadap frekuensi kekambuhan di RSJ pusat Lawang dan RSJ daerah Surabaya" Penelitian ini adalah penelitian korelasi. Hasil penelitian ini menunjukkan bahwa tidak ada hubungan antara tingkat pengetahuan dan tingkat penerimaan keluarga terhadap penderita gangguan jiwa dengan frekuensi kekambuhan.

\section{KESIMPULAN}

1. Tidak terdapat hubungan antara dukungan emosional dengan pasien skizofrenia di UPTD Puskesmas Sibulue Kecamatan Sibulue Kabupaten Bone.

2. Tidak terdapat hubungan antara dukungan informasional dengan pasien skizofrenia di
UPTD Puskesmas Sibulue Kecamatan Sibulue Kabupaten Bone.

3. Tidak terdapat hubungan antara dukungan instrumental dengan pasien skizofrenia di UPTD Puskesmas Sibulue Kecamatan Sibulue Kabupaten Bone.

4. Tidak terdapat hubungan antara dukungan penghargaan dengan pasien skizofrenia di UPTD Puskesmas Sibulue Kecamatan Sibulue Kabupaten Bone.

\section{SARAN}

1. Bagi keluarga, kiranya berperan aktif dalam mengawasi, membimbing, dan memberikan dukungan dan motivasi agar penderita skizofrenia menyelesaikan pengobatan sampai selesai dan dinyatakan sembuh oleh petugas kesehatan.

2. Diharapkan adanya upaya untuk meningkatkan peran keluarga sehingga meningkatkan kepatuhan berobat pada pasien skizofrenia.

3. Bagi peneliti selanjutnya, diharapkan kepada peneliti selanjutnya dapat meneliti lebih dalam dan lebih jauh lagi serta menggunakan analisis yang berbeda dan metode yang berbeda sehingga memperkaya analisis data penelitian serta penelitian ini dapat menjadi bahan dasar dalam penelitian selanjutnya dan menambahkan variabel independen lainnya yang berhubungan dengan kepatuhan berobat pada penderita skizofrenia

\section{DAFTAR PUSTAKA}

Puspitasari, E. P., Psikologi, F., \& Surakarta, U. M. (2009). Peran dukungan keluarga pada penanganan penderita skizofrenia, $1-10$.

Budiman, R. (2013)., \& Salemba, M. J.: (2013). Kapita Selekta Kuesioner: Pengetahuan dan sikap dalam penelitian kesehatan. Jakarta: Jakarta : Salemba.

Chao, C. J., Salvendy, G., \& Lightner, N. J. (1999). HUBUNGAN ANTARA DUKUNGAN KELUARGA DENGAN KEBERFUNGSIAN SOSIAL PADA PASIEN SKIZOFRENIA PASCA PERAWATAN DI RUMAH SAKIT. Behaviour and Information Technology, 18(6), 413-430. https://doi.org/10.1080/014492999118841

Dalem, A. A. I., Yundari, H., Made, N., Dewi, Y., Studi, P., Keperawatan, I., ... Ppni, M. (2018). FAKTORFAKTOR YANG BERHUBUNGAN DENGAN PERAN KELUARGA SEBAGAI CAREGIVER PASIEN SKIZOFRENIA, 1(1), 27-42.

Durand Mark \& Barlow David, H. (2007). Essential of Abnormal.

Elvira, S. D. dan G. H. (2010). 2010. Buku Ajar Psikiatri. Jakarta: Badan Penerbit FK UI.

Hawari, D. (2009). Psikometri Alat Ukur ( Skala) Kesehatan Jiwa. Jakarta:FKUI.

Rizqiyatiningsih, S. (2014). Hubungan Pengetahuan Tentang Gangguan Jiwa Dengan Dukungan Keluarga Yang Mempunyai Anggota Keluarga Skizofrenia Di RSJD Surakarta. Fakultas IImu Kesehatan Universitas Muhammadiyah Surakarta 2014. Retrieved from http://eprints.ums.ac.id/9479/2/J210060039.pdf 
Taufik, Y. (2014). Hubungan Dukungan Keluarga dengan Tingkat Kekambuhan pada Pasien Skizofrenia di Poliklinik Rumah Sakit Jiwa Grhasia Diy. STIKes Aisyiyah Yogyakarta, 1-15. https://doi.org/10.1016/j.rcl.2006.10.012

Wulansih, S., \& Widodo, A. (2008). Hubungan Antara Tingkat Pengetahuan Dan Sikap Keluarga Dengan Kekambuhan Pada Pasien Skizofrenia Di Rsjd Surakarta. Berita IImu Keperawatan, 1(4), 181-186.

Emotion, F. E., Patients, S., \& Frequency, R. (2012). Pengetahuan dan Ekspresi Emosi Keluarga serta Frekuensi Kekambuhan Penderita Skizofrenia, (5). 